\title{
EDITORIAL CRÍTICO OU O ENIGMA DO QUALIS
}

Inimigos da esperança - publicar, perecer e o eclipse da erudição, é o título do livro do Editor da Harvard University Press, Linsdsay Waters, publicado recentemente no Brasil. O ponto central do livro é a crítica ao sistema de avaliação das publicações científicas. A crítica reside numa constatação bastante simples: a cobrança por produtividade intelectual (modelo que justifica as hierarquias acadêmicas) é proporcional à precarização dos sistemas de avaliação. Mesmo que de forma tímida, assistimos debates semelhantes no sistema de avaliação da produção científica brasileira. A CAPES assumiu a tarefa de ordenar essa política de avaliação no Brasil. A ambição é criar um sistema suficientemente universal para avaliar e comparar a produção científica na forma de livros, periódicos e eventos. Com isso o intelectual brasileiro redefine a resposta ao enigma da esfinge: na tenra idade homem engatinha, na juventude anda sobre dois pés e na velhice apóia-se em uma bengala. Entretanto, sem publicar um artigo em uma revista Qualis não escapará do estrangulamento da feroz esfinge.

Mas nem todos podem fugir dos constrangimentos institucionais da avaliação, especialmente aqueles que estão no início da carreira. Ademais, a avaliação faz parte da natureza do trabalho acadêmico e pode ser reconfortante ou mesmo constrangedor o fato de nossos pares assumirem seu protagonismo. É com esse pensamento que indico os dois princípios que guiarão as reflexões sobre a avaliação da área de geografia:

1) Aceitar que vivemos em um momento marcado pela produtividade, índices, fator $\mathrm{H}$, o que não significa acreditar que esse momento seja imutável, pois o debate acadêmico e a ação política têm eficácia histórica comprovava.

2) Aceitar que devemos nos submeter ao sistema de avaliação dos pares, desde que estes estejam, de igual forma, descobertos do manto protetor do sistema, o que significa que podemos avaliar os avaliadores.

Com essas ressalvas passo a fazer uma reflexão sobre a classificação do Qualis geografia, publicada no site da CAPES na segunda quinzena de 
dezembro de 2008. ${ }^{1}$ A nova classificação prevê sete estratos, assim organizados: A1, A2, B1, B2, B3, B4 e B5. A localização em cada estrato é determinada por uma pontuação que varia de 0-10 (B5) até 86-100 (A1). Esse é o sistema. Uma revista A-2, por exemplo, deverá atingir uma pontuação entre 71 e 85 pontos. Os pontos possíveis são divididos em cinco critérios que indicam a qualidade do periódico. Os critérios são: Normalização, Publicação, Circulação, Autoria-Conteúdo e Gestão Editorial. ${ }^{2}$ De maneira geral tais critérios contemplam características de um bom periódico reconhecidas por qualquer editor. Mas por que, então, a divulgação da classificação causou impacto tão negativo na comunidade acadêmica, de maneira geral, e na geografia, de maneira particular? A tabela abaixo resume o resultado da avaliação da área de geografia.

\section{Quadro 01}

\begin{tabular}{|l|c|c|c|c|c|c|c|c|}
\hline \multicolumn{10}{|c|}{ SÍNTESE DA CLASSIFICAÇÃO DO QUALIS DA } \\
\hline Ainculo & A-1 & A-2 & B-1 & B-2 & B-3 & B-4 & B-5 & C \\
\hline Internacional & 18 & 27 & 41 & 18 & 21 & 7 & 02 & 00 \\
\hline Nacional & 00 & 05 & 19 & 54 & 68 & 93 & 110 & 89 \\
\hline Total & 18 & 32 & 60 & 72 & 89 & 100 & 112 & 89 \\
\hline
\end{tabular}

* Informações retiradas do site http://qualis.capes.gov.br/webqualis/. Acesso em 27/12/2008. Os totais não se referem apenas às revistas de geografia, mas de áreas como história, economia, arquitetura, sociologia, demografia, saúde etc., que foram cadastradas no Qualis-geografia.

1 O resultado da avaliação do biênio 2006-2007 foi divulgado no site da CAPES no dia 27/12/2008. Desde o mês de janeiro até o encerramento desse editorial (20/02/2009) o sistema QUALIS encontra-se em manutenção.

2 Cada um desses critérios foi subdividido em outros critérios, demarcando, na avaliação do periódico, a presença ou ausência. 1-NORMALIZAÇÃO - Legenda Bibliográfica e Ficha Catalográfica, Sumário, Normas de Publicação e Referências, Afiliação Institucional do Autor (Endereço do autor para correspondência, inclusive o eletrônico), Resumos de artigos (Inclusão regular), Descritores (palavras-chave) e Data de recebimento e aceite dos textos. 2- PUBLICAÇÃO - Tempo de publicação, Regularidade e Periodicidade (desde que cumprida no biênio). 3-CIRCULAÇÃO - Indexação em bases de dados (ISI, Scielo, Scopus ou citação em outra base bibliográfica), Formas de distribuição, Possibilidade de assinaturas, Disponibilidade em Bibliotecas do sistema nacional e ou internacional, Para revista eletrônica presença no sítio de sua instituição (Departamento, Programa, outro), Veiculação virtual e impressa, Permuta e Consultores Externos. 4-AUTORIA E CONTEÚDO - Autoria, Número médio de páginas de artigos e ensaios, Número de artigos e ensaios por ano, Relatos de experiência, resenhas bibliográficas, notas técnicas, entrevistas, etc., Representações gráficas, cartográficas e iconográficas. 5-GESTÃO EDITORIAL - Comissão executiva e/ou Editor responsável, Composição do Conselho (Reconhecida contribuição na área), Abrangência geográfica do Conselho, Critérios de arbitragem, Financiamento por agência de fomento. 
Há muitas formas de interpretar os dados, mas concentrarei as atenções em dois pontos. O primeiro é o processo de avaliação e o segundo é estratégia de área que permeia o processo.

A tarefa de avaliar periódicos não é fácil, especialmente considerando a diversidade das publicações. Mas o formulário de avaliação facilitou o trabalho. Portanto, o problema não era o como avaliar, mas o que avaliar, fato que exige conhecimento suficientemente amplo das publicações da área de geografia. A comunicação com os editores, nesse sentido, seria fundamental. Os canais como os programas de pós-graduação, a AGB ou mesmo ANPEG, poderiam ter sido utilizados para divulgar os critérios e solicitar o envio dos exemplares impressos. A discrepância, por exemplo, entre a classificação do Boletim Goiano de Geografia e a pontuação auferida pelo Conselho Editorial, nos leva a indagar o seguinte:

- A comissão teve acesso às publicações impressas?

- A comissão teve acesso às publicações eletrônicas?

- Como as políticas de permuta, intercâmbio e assinaturas foram avaliadas?

- De que forma os critérios como tempo de publicação, regularidadee periodicidade foram verificados?

Essas respostas são primárias, pois só assim poderemos avaliar e comparar as publicações, sem cair na visão substancialista de que existem periódicos, por natureza, melhores que outros. O apego à tradição é prejudicial em qualquer que seja o procedimento avaliativo. Esse fato é interessante, pois entre as incongruências na lista divulgada, estão revistas que não se encaixam nos padrões de avaliação divulgados e outras que nem sequer foram atualizadas no conteúdo, seja na versão impressa ou mesmo na digital.

O segundo ponto refere-se à estratégia de área. Na lista divulgada, especialmente nos primeiros estratos, há o predomínio de revistas internacionais (quadro 01). Não há, por exemplo, nenhuma revista brasileira classificada como A-1, fato estranho, pois aplicando as pontuações da tabela, alguns periódicos atingem o estrado de pontos para A1. A concentração das revistas de geografia brasileira aparece a partir do estrato B-3, acompanhado de outras áreas, cujos exemplos mais peculiares são os seguintes: Enfermagem Brasil (B2), Brazilian Journal of Veterinary Research and Animal Science (B3), Ciência \& Saúde Coletiva (B3), Revista de Patologia Tropical (B3), Revista Brasileira de Saúde Ocupacional (B3) etc. O critério de permeabilidade das áreas, que não consta na ficha de avaliação, deveria ser objeto de 
reflexão. Tenho dúvidas, por exemplo, se a área de saúde foi tão generosa na avaliação dos periódicos de geografia em seu sistema. Mas qual o problema de tão poucas revistas de geografia com boa classificação no novo sistema? Sabemos que nossa rotina acadêmica é marcada pelo sistema de avaliação que não atinge apenas a pós-graduação ou mesmo a concessão de bolsas de produtividade. Os editais de PIBIC, freqüentemente, utilizam essa pontuação para classificação. A matemática é simples. No Brasil, para publicar em uma revista de geografia com classificação A-2 só existem cinco endereços: Geografia - Rio Claro, Geousp - USP, Cidades - Presidente Prudente e Terra Livre - AGB, Revista Brasileira de Geomorfologia. As cinco revistas, de reconhecido prestígio, dificilmente seriam capazes de atender a demanda das publicações dos programas de pós-graduação brasileiros, fato desmotivador para um período de tanta cobrança por produtividade - não por acaso assistimos nos últimos anos uma verdadeira avalanche de livros organizados. Enfim, não se trata de defender um corporativismo de área ou mesmo que a comissão de avaliação seja omissa diante de revistas de baixa qualidade editorial, mas de aproveitar o momento de avaliação para discutir e trocar experiências sobre uma política editorial que valorize as especificidades da produção da geografia brasileira.

Qualquer processo de avaliação, para almejar justiça, deve ter regras suficientemente claras, ao ponto de serem reconhecidas como legítimas não apenas pelos avaliadores, mas também pelos avaliados. Não deveriam existir enigmas nesse processo. É isso que nos deixa preocupados, pois, ao que parece, Édipo não derrotou a esfinge e Tebas continua em perigo.

\section{Tadeu Alencar Arrais}

Coordenador Editorial do BGG

tadeuarrais@ibest.com.br 